\title{
Thriving in Complexity: A Framework for Leadership Education
}

\author{
Daryl Watkins, DM \\ Associate Professor, Department of Organizational Leadership \\ Associate Dean, College of Business \\ Embry-Riddle Aeronautical University - Worldwide \\ Matthew Earnhardt, Ph.D. \\ Assistant Professor, Department of Organizational Leadership \\ Chair, Department of Organizational Leadership \\ Embry-Riddle Aeronautical University - Worldwide \\ Linda Pittenger, DM \\ Associate Professor, Department of Organizational Leadership \\ Director of Faculty Development, College of Business \\ Embry-Riddle Aeronautical University - Worldwide \\ Robin Roberts, DM \\ Assistant Professor, Department of Organizational Leadership \\ Embry-Riddle Aeronautical University - Worldwide \\ Kees Rietsema, Ph.D. \\ Associate Professor, Department of Organizational Leadership \\ Embry-Riddle Aeronautical University - Worldwide \\ Janet Cosman-Ross, Ed.D. \\ Assistant Professor, Department of Organizational Leadership \\ Embry-Riddle Aeronautical University - Worldwide
}

\begin{abstract}
Technological advances, globalization, network complexity, and social complexity complicate almost every aspect of our organizations and environments. Leadership educators are challenged with developing leaders who can sense environmental cues, adapt to rapidly changing contexts, and thrive in uncertainty while adhering to their values systems. In a complex leadership context, inadequate leader responses can result in devastating organizational impacts akin to the butterfly effect from chaos theory. This paper advances a simple model for leadership education based on a program we designed to develop leaders who understand the nature of complex systems, reliably use their ethical value systems, are emotionally intelligent and resilient, and can adapt to emergent situations.
\end{abstract}

On September 15, 2008, Lehman Brothers Holdings, Inc. filed for Chapter 11 bankruptcy protection, ranking as the largest corporate bankruptcy filing in U.S. history. The filing, for many, serves as a symbol of corporate greed and the standard-bearer of the subprime mortgage crisis (Walker \& Earnhardt, 2015). Symbols do not equate to reality and the real story behind 
Lehman Brother's demise is infinitely more nuanced and complex than sound bites suggest. One of our coauthors was responsible for facilitating the process to layoff several thousand Lehman employees in the weeks leading up to and after the formal bankruptcy filing. Such notices went to blameless employees who were performing their jobs the same as millions of other people do every day. Like thousands of other organizations, Lehman operated in an increasingly dynamic industry with a progressively complex business model. In such an environment, a small trigger can generate large consequences (Lorenz, 1972). For Lehman Brothers, the fourth largest U.S. investment bank, the unethical decisions of a few, resulted in ripples and negative consequences that reverberated across the global financial markets, causing major system disruption.

The essential and simple leadership lesson from the Lehman collapse is that the top executives did not adhere to Lehman Brothers' core values (L.M. Pittenger, personal communication, April 22, 2017). Consequently, Lehman Brothers employees did not have appropriate processes in place to ensure sound business practices and compliance with federal regulations. Instead, the greed of a few led to a culture of excessive risk tolerance as evidenced by an increase in the Leverage Ratio from 23.7x to 30.7x between 2003 and 2007. Lehman also grew an astounding $75 \%$ in those five years, increasing employee count from 16,188 employees to 28,556 employees (Lehman Brothers, 2007). The weight of the corporate ship had become too heavy and the ship's captains resorted to desperate measures to keep it afloat, contributing to the subprime calamity and the financial meltdown of 2007-2008.

The Lehman Brothers story represents thousands of examples of organizations that struggle to adapt in an increasingly complex environment. People yearn for simpler times when organizations relied on thoroughness, stability, and certainty of tasks and decisions that could be traced to positive outcomes. Many organizations operate in an exploratory, innovative mode, desiring speed over reliability. The competing tension between simplicity and safety as well as innovation and speed have intensified, forcing leaders to adapt their styles, their approaches, even themselves, to their contexts.

This paper advances a simple model for leadership education based on elements of our program design. Our industry stakeholders challenge us with developing leaders who can sense environmental cues, adapt to changing contexts, and thrive in uncertainty while adhering to their values systems. Therefore, in our program, we develop leaders who understand the nature of complex systems, reliably use their ethical value systems, are emotionally intelligent and resilient, and who can adapt to emergent situations.

There has been a tendency for organizations to shorten strategic planning horizons from 15 years or greater down to 3-5 years (Sołoducho-Pelcd, 2015) while having access to more data about their competitors, their environment, and even their own organizations. Even with the shorter planning horizons, strategic plans are often dead on arrival (Roth, 2015). In earlier years, organizations promised employees lifetime employment and leaders were cultivated from within the ranks. Universities focused on developing business acumen through business degrees and left leader development to the organizations. Observers often react to high profile corporate malfeasance (i.e., Enron, Lehman Brothers, and Wells Fargo) with renewed calls for ethics training in MBA programs. However, we see it differently; we see a need for an intentional and structured leadership development education that focuses on complexity, ethics, emotional 
intelligence, and leading in complex adaptive environments.

We propose that an understanding of systems behavior and complexity concepts are essential aspects of leader development. Climate change, unequal wealth distribution, national health care, illegal immigration, resurgent populism, racial injustice and inequalities, gender discrimination, and other problems of national and global significance are substantial system based issues. Yet, even these challenges are often treated and discussed in reductionist terms as if the issues could be solved as separate and unrelated. Even outside the national and global context, the lack of systems perspective occurs at every level, including personal and organizational. Leaders who see the world through the lens of complexity, as opposed to predictable and linearly, are more inclined to probe, sense, and respond than to force comfortable, but inadequate, solutions. Additionally, we see a strong connection between successful leadership in complex adaptive environments, emotional intelligence, and ethics education.

The connection between successful leadership in complex adaptive environments, emotional intelligence, and ethics education may not be immediately obvious. Emotional intelligence consists of self-awareness, self-regulation, empathy, and social skills (Goleman, 1998). Emotional intelligence competencies are necessary for a leader to be successful in reflecting on experience, interpreting environmental cues, relating to followers, and developing relationships. These activities are important for any leader, but are even more important in a complex environment where the best solutions typically generate from deep within organizations and leaders must be able to suspend egos to allow all opinions to be heard. Self-awareness, selfregulation, and empathy are also important in allowing a leader to develop and adhere to an ethical point of view, whether that view is formulated from values, duty, or consequences. We develop leaders who have put considerable reflection and thought into developing and applying their ethical frameworks so that these frameworks are part of their decision-making processes and not afterthoughts. Consideration of an ethical framework is not trivial given the extreme negative impacts of ethical breaches on national systems (e.g., financial markets, banking systems, transportation, and water quality).

\section{Literature Review}

In this section, we describe the literature on complex environments, ethics, emotional intelligence, and complex adaptive leadership.

Complex Environments. With roots in cybernetics, theoretical biology, and systems study (Larson, 2016; McKelvey, 2004); complexity has affected all sciences, from quantifiable and quantitative work to qualitative research, both primary and applied. For example, "questions in physics and chemistry are no longer ones of 'deduction', but of wondering what is relevant and how" (Stengers, 2004, para. 2). In understanding complexity, noting that there are different principles between disciplines is important (Stengers, 2004). Nevertheless, scientists from the Santa Fe Institute (n.d.) have attempted to merge approaches from different scientific disciplines 
and believe they are close to a general complexity theory.

The objective of such a theory would be to interpret and perhaps even anticipate the behavior of systems and multiple phenomena. Notwithstanding the Institute's efforts, some general themes run through any description of complexity, including emergence, networked structure, unpredictability, autonomous agents, self-organization, and chaos (Marion \& UhlBien, 2001). To the degree that complexity theory intersects with organizational theory and theories of leadership, it is important to note that complex systems are also learning systems (Marion \& Uhl-Bien, 2001). Such systems are often characterized as more horizontal and crossfunctional organizations which are adaptable and flexible in their own right. Complex systems may also exist within complex environments evidenced by multiple agents and continuous change (Uhl-Bien \& Marion, 2009). For example, a business market environment constantly adapts to fluctuating consumer demand as well as the cross currents of competition. Other factors such as government regulation, economic conditions; and manufacturing concerns may introduce further complexity (Hannah, Campbell \& Matthews, 2010).

To a large degree, we have grown up in and are schooled along the lines of a world that is linearly organized and "works" according to traditional principles of cause and effect. The western worldview places great confidence in the scientific method and all that it implies...the so-called Newtonian view of the world. Complexity-based models reinterpret these principles on a grand and all-encompassing scale. For example, in a relatively simple and easily understood method, the Cynefin Framework design by Snowden and Boone (2007) permitted us to envision problems and situations in ways that allow for the vagaries of simple, complicated, complex and chaotic contexts (Childs \& McLeod, 2013). This tool is one of many that allows us to negotiate a contextually complex world, analyze our situations according to relevant descriptors and then act (lead) in ways that are relevant and appropriate. Snowden and Boone (2007) posited that an understanding of the situation allows us to act in ways that are not necessarily instinctual, but are more clearly aligned with the exigencies of the circumstances at hand. Therefore, complexity has direct application in ethics and leadership theory (Uhl-Bien, Marion, \& McKelvey, 2007).

Ethics. Ethical theory and leadership practice are interrelated (LaFollette, 2007) such that ethics is an important component of leadership behavior and responses. Ethics is critical to leadership and an understanding of normative judgement of right and wrong choices is important to that understanding (Jonsson, 2011). An abundance of literature exists in regards to ethical theories, but each principle generally falls into one of three categories: aretaic, deontological, or teleological.

Aretaic ethics is the normative virtue-based category of ethical theories. In this sense, virtue is not an abstract concept. Aristotle held that certain virtues were necessary to achieve "the good life"' (Koch \& Menezes, 2015, para. 13). Virtues such as temperance and courage are acquired through habit (Bennett, 2011). Virtues such as courage, fairness, generosity and patience are exercised in particular situations (Annas, 2015). Thus, acting with courage, fairness, and generosity would demonstrate ethical leadership and lead to the good life.

Deontology, or duty-based ethics, focuses on morally obligatory action. Kantian ethics are the most well know example of deontology, which suggests that we should act according to 
what we believe are universal rules for the situation and that human behavior should be governed by the morality of the choices that we make (Carroll \& Buckhholtz, 2015). Kantian leaders aim to develop empowered, responsible followers (Ciulla, Uhl-Bien, \& Werhane, 2013). The common theme of deontological theories is that we have a duty to perform the right actions and to avoid the wrong ones (Pojman, 2012), independent of the consequences. This is in stark contrast to teleological theories.

The teleological concept of ethical behavior is based on consequences of one's actions rather than principles or duties (Carroll \& Buchholtz, 2015). Utilitarianism, the most well-known consequentialist theory is associated with John Mill, who maintained that we are ethically obligated to do what is best for the greatest number of people (Lipari, 2017). According to Smart and Williams (1973), "utilitarianism is the view that the rightness or wrongness of an action depends only on the total goodness or badness of its consequences" (p. 4). Leaders using a utilitarian framework are forced to think of the good of others (Carroll \& Buchholtz, 2015). The other end of the teleological spectrum is ethical egoism, which says we ought to do what is in our own best interest; that promoting oneself is in accordance with morality (IEP, n.d.). LaFollette (2007) posited that leaders promote ethical behavior only when it serves to advance their interest and that ethical egoism (many philosophers repudiate this) drives decision-making. In this view, although we believe we act out of concern for others or from our commitment to moral principle, it is our beliefs and self-interest that drive how individuals act.

The Role of Emotional Intelligence. Leaders often find themselves in novel situations where no rules or precedent exists. Conflicting moral rules often leads to objectionable results, challenging such theories. As such, situational sensitivity becomes the "rule of thumb," where abridged principles are acceptable and relatively context free (Schneewind, 1993) and one's level of emotional intelligence can affect the course of an ethical decision, determining the best leadership action. In an unpredictable external environment, today's leaders live in a real time changing environment, resulting in stress that affects leadership responses. The constant pressure that leaders face can diminish their willpower to act ethically (Joosten, Van Dijke, Van Hiel \& DeCreamer, 2014) and may lead them to act unethically or immorally.

McKee, Boyatzis, and Johnson (2008) emphasized that "we actually feel before we think" (p. 27), setting the foundation for the role of competencies in how leaders respond to complexity. Competencies such as self-awareness, self-management, social awareness, and relationship management enable leaders to remain calm in times of complexity, by managing their own internal responses, moods, and states of mind (Boyatzis \& Akrivou, 2006). Notably, self-awareness is the foundation of emotional intelligence (McKee, Boyatzis, \& Johnson, 2008) and leaders who recognize their own values, principles, strengths, and limitations are more selfconfident. Self-confidence is a key driver to how leaders ultimately handle stress and responses (Cherniss \& Goleman, 2001).

Boyatzis and McKee (2005) cited stress as the biggest culprit of dissonant behavior and described the "sacrifice syndrome" as an abundance of stress that goes unchecked. The "sacrifice syndrome" is a vicious cycle of stress and sacrifice that results in mental and physical distress, burnout, and less effectiveness (McKee, Boyatzis, \& Johnson, 2008). Thus, the sacrifice syndrome can be insidious, changing how leaders think and act before they realize what is 
happening. McKee, Boyatzis, and Johnson, (2008) claimed ego defense mechanisms create illusions in self-perception, causing leaders to develop a distorted self-image. Many leaders fall victim to the sacrifice syndrome and their behavior becomes unethical (George, 2011) as demonstrated by several high profile resignations in the U.S. business community in the early 2000's. Examples include Mark Hurd, Hewlett-Packard CEO, for submitting false expense reports concerning his relationship with a contractor; U.S. Senator John Ensign for covering up an extramarital affair with monetary payoffs; and Lee B. Farkas, the former chairman of Taylor, Bean \& Whitaker, found guilty of bank fraud schemes.

Leaders ultimately become ineffective unless they have regular cycles of renewal (Boyatzis \& McKee, 2005). Renewal starts with mindfulness, a process of becoming aware of one's thoughts and emotions. Consciously engaging emotions such as hope and compassion can increase our resilience and counter the physiological and psychological effects of stress (Boyatzis, 2008). To build resilience, Boyatzis (2008) suggested focusing on desirable and sustainable change in one's behavior, thoughts, feelings, and perceptions, a process called Intentional Change Theory (ICT). By visualizing one's "ideal self" and identifying the gap between the ideal self and one's "real self", leaders can understand what they need to learn to execute a change. Such understanding is necessary to link intrinsic motivation with the drive to change behaviors (Boyatzis \& Akrivou, 2006). The execution to become the ideal self can be difficult due to a lack of support, or repeated failures. Leaders must experiment to determine the most effective practices to sustain the desired change and establish relationships that will support the totality of the intentional change. Consequently, the intentional change process is often experienced as epiphanies or a set of discoveries (Boyatzis, 2006).

Complex Adaptive Leadership. Uhl-Bien, Marion and McKelvey (2007) indicated that most leadership models have focused on top-down, bureaucratic structures which no longer work in complex contexts. A different paradigm focused on adaptive outcomes (with an emphasis on context) is needed. Traditional leadership is losing relevance and developing the competence of adaptive leadership is critical for effective success (Apenko \& Chernobaeya, 2016). Complex adaptive leadership provides a systems view of leadership (Hannah, Campbell \& Matthews, 2010) that moves away from a linear view of the world and focuses leaders on the complex and dynamic nature of the environment (Marion \& Uhl-Bien, 2001). Uhl-Bien et al. (2007) distinguished complex adaptive leadership theory as focused on the dynamic and complex systems that comprise leadership. Leaders act within this system to influence the system and outcomes. Complex Adaptive Leadership occurs through solving adaptive challenges (requiring new learning, innovation, and patterns of behavior) and not through technical problems.

As stated by Marion and Uhl-Bien (2001) "leaders are part of a dynamic rather than being the dynamic itself”' (p. 414). In a complex adaptive leadership framework, the assumption that the leader has the answer is false (Weberg, 2012). A leader should network with the team to exchange information and knowledge to improve outcomes. Chadwick (2010) indicated that to respond to complexity, a shared governance model that empowers employees to own their workplace and adapt to changes is important. A team needs to constantly scan the environment for changes (Edson, 2012). Uhl-Bien and Marion (2009) took this a step further and indicated that creative, adaptive organizations operate across boundaries, functions, and roles and blend of structured and dynamic environments. Creative organizations operate in an informal way, often 
with boundaries that are blended and fuzzy (Uhl-Bien \& Marion, 2009). Informal networks and dynamics should be nurtured and valuable to ensuring effective change. Effective leaders allow members to provide each other with direction and purpose in responding to adaptive challenges, which is important to cultivating and maintaining high quality exchanges at all levels of the network (Hannah et al, 2010). In other words, leaders should create transformational environments as a way to foster conditions to adapt to change rather than try to control change (Marion \& Uhl-Bien, 2001). Individuals work together to adapt rather than relying on one specific leader to constantly react to and respond to change (Uhl-Bien \& Marion, 2009).

Leadership Education Program. The complex and changing world is causing global shifts in how people are connecting in leader-member exchanges, developing capabilities, and organizing their cultures (Sowcik, Andenoro, McNutt, \& Murphy, 2015). Leadership educators are considering the role of complexity in leadership education that is active, engaging, and provides real-time insight (Schuyler et al., 2016). Real-time connected learning focuses on increasingly complex environments where change (rapid, persistent, and filled with people, tasks, and business relationships) often results in ethical challenges.

The pace of change, cross-pollination of cultures, emerging technologies, the Internet of Things, digital business, and developing social societies are binding humans to informationladen ecosystems they may not be mature enough to handle (Roberts, 2015). Leadership education should stimulate real-time learning that maximizes academic engagement and promotes agility and adaptability, leading to broadened competencies. Sowcik et al. (2015) suggested that engaged leadership education and development be designed to produce competencies in complex adaptive leadership such as: (a) communication (language, verbal/writing, non-verbal/cueing, thinking/emotions, listening), (b) science (curiosity and ability to judge validity), (c) thinking and reason (mindfulness, macro-level thinking, complexity, context, questioning/assumptions), and (d) problem solving and self-discipline. Schulyer Baugher, and Jironet (2016) suggested that leadership education concentrate on the essence of complexity as it unfolds in adaptive human environments. They recommend that curriculum and even assessment move away from teaching about "effectiveness" and focus on complexity.

Our leadership development program offers a simple model (see Figure 1) to help our students develop repeatable, thoughtful responses to challenging ethical dilemmas in complex situations. The model is not proscriptive in that it does not suggest a particular action; instead, the model presents a perspective on how to approach the ethical decision-making process. We teach ethical reasoning and challenge students to think through situations and cases studies using multiple ethical lenses (Watkins \& Earnhardt, 2015). We also teach complex adaptive leadership principles and we incorporate systems thinking into the program. Finally, we coach our students to become leaders who have high levels of self-regulation, self-awareness, empathy, and social skills. 


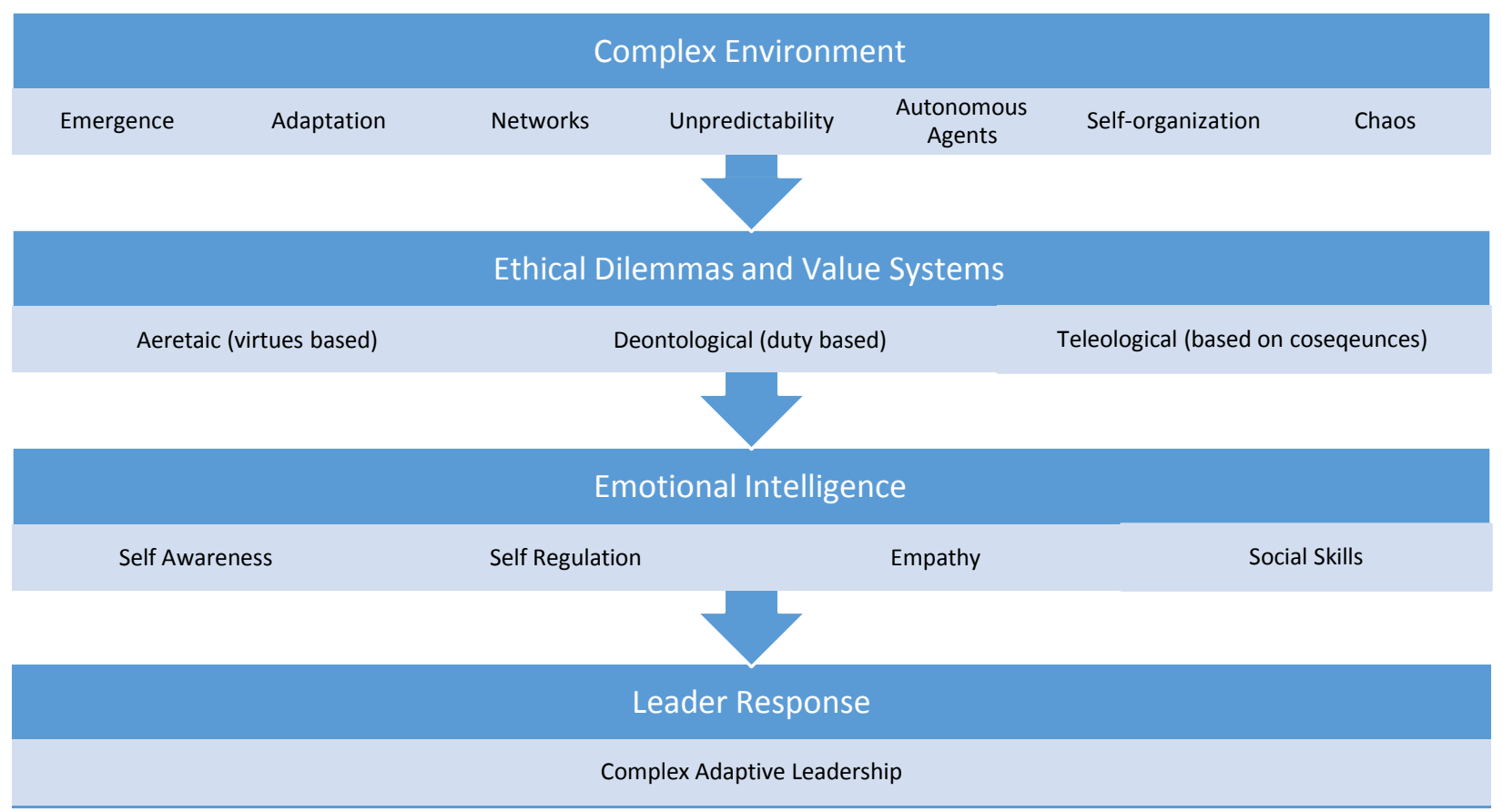

Figure 1. Leadership response model depicts relationships between complexity, ethical dilemmas, emotional intelligence, and leadership response.

\section{Discussion}

Leadership theories represents an evolving set of constructs. Early leadership theories focused on individual leaders as exemplars. Scholars attempted to find specific traits, then behaviors, that captured the ideal leader. Subsequent theories considered task or people focus, contingencies and situational aspects, and the quid pro quo exchanges between leaders and followers. Shortcomings in the early leadership models guided researchers to examine the relational aspects between leaders and followers. Modern theorists focused on how leaders interacted with their followers to develop personal and organizational capacities and whether the leader focused on follower needs (e.g., transformational leadership, servant leadership). More recently, leadership scholars have sought to understand how leaders succeed in certain contexts (e.g., crisis leadership, complexity leadership).

Leaders and leadership theory have not kept pace with the rapidity of change or with the increasingly complex nature or leadership contexts. Consequently, leaders are more at risk of failing to understand their contexts and of developing inadequate behavioral responses. Ethical dilemmas further confuse and exacerbate these inadequate behavioral responses by offering unclear and unpredictable outcomes. Communication technologies, including social media and cable network news, further complicate outcomes by making it easy to hold every decision up for scrutiny and debate.

For example, the viral spread of the cell phone video of Chicago Aviation Security Officers dragging a United Airlines passenger off a plane serves as a cautionary tale for the power of social media to create an immediate negative impact on a respected brand. United 
Airline policies, decision-making at the gate, and a vacillating public affairs response exacerbated the incident into a crisis. The New York Times reported that United lost nearly 1 billion dollars in market capitalization the day following the incident and announced that the CEO, Oscar Munoz, would not become the Chair of the Board of Directors, as had been planned (Meier, 2017). Munoz failed to understand how the public would react to the incident and committed the unrecoverable error of placing public blame on the customer. The incident highlighted the complex nature of the aviation industry and the potential whole system effects of a single decision.

Complex adaptive leadership is an emerging construct. Scholars are attempting to develop an overarching theory for leading in complex environments drawing inspiration from complexity, biology, and leadership. Leadership scholars draw heavily upon complexity theory to describe common elements of a complex environment: emergence, adaptation, unpredictability, seeming randomness, patterns become obvious only after the fact, sensitivity to initial conditions, and both the system and the environment interact and can influence each other. Thus, complex adaptive leadership values adaptability, pattern sensing, and emotional intelligence. These skills and competencies enable leaders to navigate through emergent contexts while engendering the trust of their followers.

Leadership Development Program Design. Students shared that our leadership program curriculum provided them with the courage, confidence, and self-efficacy of leading themselves and others ethically in complex adaptive environments. The program design integrates online instruction with experiential learning so that students immediately incorporate learned concepts into leadership behaviors in the workplace. Students comment that a concept they learned on Monday can be immediately put in practice. The direct and real-time application inspires our students and enhances the perceived value and applicability of the program. Students are challenged to think through situations and cases using ethical reasoning. By teaching complex adaptive leadership and emotional intelligence principles, students synthesize their learning in systems thinking along with self-regulation, self-awareness, empathy, and social skills. The program outcomes focus on: (a) core leadership knowledge, (b) personal transformation, (c) group transformation, (d) organizational transformation, (e) transferability of concepts and (f) leadership sense-making. The outcomes of the program focus on application of skills in a complex adaptive world. One student stated, "[The program] forced us to think about the application of the skills we learned. We weren't just reading about concepts; we were thinking of how the concepts could be used in different scenarios."

Coursework and activities provide students with opportunities to explore the context of leader/member exchanges within real-world settings. Assignments help participants develop new mental models that consider leader/member exchanges and the impact in a complex environment. An example is the concept that effective decision-making should be driven from the bottom to the top (Uhl-Bien et al., 2007). Students working in leader-member exchanges are empowered to integrate their knowledge and skills. One alumnus shared, "we have been asked to mentor current students to become lifelong learners and to share that knowledge with others. I am definitely willing to continue mentoring as long as the program continues." A current student said, "The courses offer me true insight into leading teams. We had group assignments that further emphasized the need to communicate openly and fairly. I am much better prepared in my 
leadership".

The energy the students displayed to balance work with academic pursuits was heightened by the delivery of instruction from professors who specialized in student engagement, classroom management, andragogy, and leadership education. Individuals who have mastered teaching complexity, leadership, and ethics are the best qualified to teach leadership courses (Rowland, 2016). Experiential encounters can trigger our intentional minds to engage with learning and then immediately use what is learned. That type of engaged learning also becomes a living laboratory to examine human adaptation to complex experiences. Coursework nurtures and celebrates different and unique perspectives while valuing the ideas and efforts of individual contributors in a safe and non-judgmental environment. Assignments promote civility and respect so that stakeholders enjoy meaningful and relevant experiences.

Student and Alumni Program Experiences. Alumni from the aforementioned leadership program shared success stories from their efforts integrating program learning into their leadership practices. One alumnus shared how he has incorporated complex adaptive leadership concepts into his team formation and leadership processes. He routinely takes the time to observe and reflect on how his team is responding to complex issues and where there might be potential for ethical missteps. He also sees how it is necessary for him to involve his team in decision making so that he can coach them to higher levels of understanding of the business.

Another alumnus wrote to us about how he routinely uses Complex Adaptive Leadership concepts and the Cynefin framework to frame his approach to project startup activities. Prior to learning Cynefin concepts, he and his team had attempted to define and deploy best practices for every project. Once he became aware that some contexts do not call for best practices, he learned to examine the contextual clues prior to defining an approach. He described how he had developed the confidence, emotional intelligence, and humility to admit the previous errors to his team. His followers developed more respect for him and his superiors see him as more capable and competent.

One alumna is a director at an acute care facility. She is responsible for revenue of the 195-bed facility. She described how learning about complexity, ethics, and systems have enabled her to slow down her environment. Things happen just as fast; but she has the sense of an enhanced understanding of her environment that makes events seem to be happening at a slower pace. The decisions she makes are still difficult and stressful, but she now has the confidence to seek counsel and involve community stakeholders when necessary, to communicate the decisions and the rationale behind her decisions, and to be able to maintain her own sense of values.

\section{Implications}

In this paper, we constructed a conceptual framework suggesting that complexity theory, ethical frameworks, emotional intelligence, and complex adaptive leadership are essential components of a robust leadership education. Adapting our proposed framework would require program administrators to begin to include these areas of study within their leader development programs. Furthermore, tools should be developed to measure success in learning these topics. Many leadership education programs cover ethics and emotional intelligence. However, most do 
not cover systems behavior, complexity, complex adaptive leadership, or the interrelationship of these concepts. Anecdotal evidence from our program indicates that alumni benefit from our model. Additional research is necessary to demonstrate how strengthening education in complexity, ethics, emotional intelligence, and complex adaptive leadership will influence leadership effectiveness.

The conceptual framework presented here could also be refined to demonstrate directions and strength of influence. This would be helpful to determine if more or less emphasis should be placed on specific aspects of the model. We also teach competencies (i.e., communication and critical thinking) that are not discussed in this model. Additional research is necessary to ensure other leadership competencies do not moderate the effects of our model.

Leaders should also be mindful to ensure that they have properly educated themselves in these topics. The formal education that students receive through our model is invaluable to understanding their environment and having the ability to react to our complex world. The knowledge of ethics, complexity, emotional intelligence, and complex adaptive leadership along with other concepts not explicitly mentioned in this paper develops a well-rounded leader which is invaluable to personal and professional leadership. The implications for individuals is an understanding of how these concepts allow individuals to slow down their thinking in order to speed up decision processes.

Organizations should be aware of these concepts and integrate them into hiring and other management practices. This would require that organizations understand the effects of systems, complexity, emergence, ethical malfeasance on effectiveness and profitability. Organizations could adopt this model in their leader development and management processes. For example, instead of requiring employees to simply attend an annual ethics refresher course, employees could be challenged with a workshop that featured adaptive challenges that treated emotional intelligence, ethical values, and complexity principles. Our model, if implemented, leads to better thinking and decision making.

\section{Conclusion}

This paper advanced a simple model for leadership education based on a program we designed to develop leaders who understand the nature of complex systems, reliably use their ethical value systems, are emotionally intelligent and resilient, and who can adapt to emergent situations. We proposed that systems behavior and complexity concepts are essential aspects of leader development. Leaders with foundational knowledge in these areas should be prepared to experience leadership contexts as complex and design leadership responses that predict system effects. Leaders must have high levels of emotional intelligence (i.e., self-awareness, selfregulation, empathy, and social skills) to have sustained success in complex adaptive situations. 


\section{References}

Annas, J. (2015). Applying virtue to ethics. Journal of Applied Philosophy, 32(1), 1-14. doi:10.1111/japp.12103

Apenko, S., \& Chernobaeva, G. (2016). The influence of complex adaptive leadership on the efficiency of business management. International Conference on Management, Leadership \& Governance, 17.

Bennett, F. J. (2011). The virtuoso human: A virtue ethics model based on care. Retrieved from http://scholarcommons.usf.edu/cgi/viewcontent.cgi?article=4202\&context=etd

Boyatzis, R. E. (2008). An overview of intentional change from a complexity perspective. Journal of Management Development, 25(7), 607-623. doi: 10.1108/02621710610678445

Boyatzis, R. E., \& Akrivou, K. (2006). The ideal self as the driver of intentional change. The Journal of Management Development, 25(7), 624-642.

doi:http://dx.doi.org.ezproxy.libproxy.db.erau.edu/10.1108/02621710610678454

Boyatzis, R. \& McKee, A. (2005, Oct 27). Resonant leadership: Renewing yourself and connecting with others through mindfulness, hope and compassion. Harvard Business Review Press, 1 edition

Carroll, A. \& Buchholtz, A. (2015). Business and society: Ethics, sustainability, and stakeholder management (9th ed.). Stamford, CT: Cengage Learning.

Chadwick, M. M. (2010). Creating order out of chaos: A leadership approach. AORN Journal, 91(1), 154-170. doi:10.1016/j.aorn.2009.06.029

Cherniss, C, \& Goleman, D. (2001). The Emotionally Intelligent Workplace: How to Select for, Measure and Improve Emotional Intelligence in Individuals, Groups, and Organizations. San Francisco: Jossey-Bass

Childs, S., \& McLeod, J. (2013). Tackling the wicked problem of ERM: Using the Cynefin framework as a lens. Records Management Journal, 23(3), 191-227. doi:10.1108/RMJ07-2013-0016

Ciulla, J. B., Uhl-Bien, M. \& Werhane, P. H. (Eds.) (2013). SAGE benchmarks in leadership: Leadership ethics (Vols. 1-3). London: SAGE Publications Ltd. doi: $10.4135 / 9781446286357$

Edson, M. C. (2012). A complex adaptive systems view of resilience in a project team. Systems Research and Behavioral Science, 29(5), 499-516. doi:10.1002/sres.2153

George, B. (2011, June 6). Why Leaders Lose Their Way. Retrieved from hbswk.hbs.edu: http://hbswk.hbs.edu/item/why-leaders-lose-their-way 
Goleman, D. (1998) Working with Emotional Intelligence. New York: Bantam Books. Chicago

Goleman, D. (2009). What is Inspirational Leadership? Retrieved January 24, 2017, from Hay Group: http://atrium.haygroup.com/us/video/video_popup.aspx?id=19What_is_inspirational_lea dership_480x360.flv

Hannah, S. T., Campbell, D. J., \& Matthews, M. D. (2010). Advancing a research agenda for leadership in dangerous contexts. Military Psychology, 22(sup1), S157-S189. doi:10.1080/08995601003644452

IEP (n.d.) Internet Encyclopedia of Philosophy, a Peer-Reviewed Academic Resource. Retrieved from: http://www.iep.utm.edu/egoism/\#SH2b

Jonsson, P. O. (2011). On utilitarianism vs virtue ethics as foundations of economic choice theory. Humanomics, 27(1), 24-40. doi:http://dx.doi.org.ezproxy.libproxy.db.erau.edu/10.1108/08288661111110150

Joosten, A., Van Dijke, M., Van Hiel, A., DeCreamer, D. (2014) Being “'in Control” May Make You Lose Control: The Role of Self-Regulation in Unethical Leadership Behavior. Journal of Business Ethics 121:1-14 DOI 10.1007/s10551-013-1686-2

Kant, I. (1999) Grounding for the Metaphysics of Morals, $3^{\text {rd }}$ Edition. Indianapolis: Hackett.

Kezar, A. J., Carducci, R., \& Contreras-McGavin, M. (2006). Rethinking the" L" word in higher education: The revolution of research on leadership: ASHE higher education report. John Wiley \& Sons.

Koch, K. \& Menezes, C. (2015). Virtue ethics: Beyond moral theory. South African Journal of Bioethics and Law 8.2 (Nov 2015)

LaFollette, H. (2007) “The Practice of Ethics” Oxford: Blackwell Publishing.

Larson, C. S. (2016). Evidence of shared aspects of complexity science and quantum phenomena. Cosmos and History: The Journal of Natural and Social Philosophy, 12(2), 160.

Lehman Brothers Holdings Inc. (2007). Annual report 2007. Retrieved from http://www.secinfo.com/d11MXs.t5Bb.htm\#1stPage

Lipari, L. (2017) Communication ethics. In Oxford Research Encyclopedia of Communication. Feb 2017 DOI: 10.1093/acrefore/9780190228613.013.58 Retrieved from http://communication.oxfordre.com/view/10.1093/acrefore/9780190228613.001.0001/acr efore-9780190228613-e-58 
Lorenz, E. (1972). The butterfly effect: Does the flap of a butterfly's wing in Brazil set off a tornado in Texas. The Chaos Avant-garde: Memories of the Early Days of Chaos Theory. World Scientific.

Marion, R., \& Uhl-Bien, M. (2001). Leadership in complex organizations. The Leadership Quarterly, 12(4), 389-418. doi:10.1016/S1048-9843(01)00092-3

McKee, A., Boyatzis, R., \& Johnson, F. (2008) “Becoming a Resonant Leader” Harvard Business Press.

McKelvey, B. (2004). Toward a complexity science of entrepreneurship. Journal of Business Venturing, 19(3), 313-341. doi:10.1016/S0883-9026(03)00034-X

Meier, B. (2017). Oscar Munoz won't get planned promotion to chairman of United. Retrieved from https://www.nytimes.com/2017/04/21/business/united-airlinesceo.html?ref=todayspaper\&_r=0

Mittal, R., \& Dorfman, P. W. (2012). Servant leadership across cultures. Journal of World Business, 47(4), 555. doi:10.1016/j.jwb.2012.01.009

Pojman, L., (2012). Ethics: Discovering right and wrong - 7th edition. Belmont, CA: Wadsworth, Inc.

Richardson, J. (2013). It's time for pervasive leadershp. Retrieved from http://azuregate.net/2013/01/07/its-time-for-pervasive-leadership/

Roberts, R. (2015). Law of thrive. Creating sustainable diverse and inclusive communities using Human Utility Business ${ }^{\mathrm{TM}}$. HR Florida Review, Fall 2015, 10..

Roth, W. F. (2015). Strategic planning as an organization design exercise. Performance Improvement, 54(6), 6-12. doi:10.1002/pfi.21487

Rottisi-Steele, G. Encyclopedia of strategic leadershp management. DOI 10.4018/978-1-52251049-9.ch009

Rowland, D. (2016). Why leadership development isn't developing leaders. Harvard Business Review, October 2014. Retrieved from https://hbr.org/2016/10/why-leadershipdevelopment-isnt-developing-leaders

Santa Fe Institute. (n.d.). Architectures of complexity. Retrieved from https://www.santafe.edu/research/themes/architectures-complexity

Schneewind, J. (1993). "Moral Knowledge and Moral Principles" in S. Hauerwaus \& A. McIntyre (eds.) Revisions. Notre Dame, IN: University of Notre Dame Press. 
Schuyler, K.G., Baugher, J.E., Jironet, K. (2016). Creative social change. Leadership for a healthy world. Emerald Group Publishing Limited: Binkley, UK.

Smart, J., \& Williams, B. (1973). Utilitarianism: For and against. Cambridge University Press.

Snowden, D.J., \& Boone, M.E. (2007). A leader's framework for decision making. Harvard Business Review, 85(11), 68-76.

Sołoducho-Pelc, L. (2015). Planning horizon as a key element of a competitive strategy. Journal of Economics, Business and Management, 3(2) 161. doi: 10.7763/JOEBM.2015.V3.174

Sowcik, M., Andenoro, A.C., NcNutt, M., and Murphy. S.E. (2015). Leadership 2050. Critical challenges, key contexts, and emerging trends. Emerald Group Publishing Limited: Binkley, UK.

Stengers, I. (2004). The challenge of complexity: Unfolding the ethics of science in memoriam Ilya Prigogine. Emergence: Complexity and Organization, 6(1), 92.

Uhl-Bien, M., \& Marion, R. (2009). Complexity leadership in bureaucratic forms of organizing: A meso model. The Leadership Quarterly, 20(4), 631-650. doi:10.1016/j.leaqua.2009.04.007

Uhl-Bien, M., Marion, R., \& McKelvey, B. (2007). Complexity leadership theory: Shifting leadership from the industrial age to the knowledge era. The Leadership Quarterly, 18(4), 298-318. doi:10.1016/j.leaqua.2007.04.002

Walker, S. M., \& Earnhardt, M. P. (2015). Sustaining an organization in the midst of chaos: Using the interconnected nature of systems to effectively respond to crises. Graziadio Business Review, 18(1). Retrieved from: http://gbr.pepperdine.edu/2015/06/sustaining-an-organization-in-the-midst-of-chaos/

Watkins, D. V. \& Earnhardt, M. P. (2015). Developing critical thinking within a Master of Science in Leadership program. Academy of Educational Leadership Journal, 19(1), 184194.

Weberg, D. (2012). Complexity leadership: A healthcare imperative. Nursing Forum, 47(4), 268277. doi:10.1111/j.1744-6198.2012.00276.x 


\section{Author Biographies}

Dr. Daryl Watkins is the Associate Dean of the ERAU-W College of Business and a tenured, Associate Professor of Leadership. He has a DM in Organizational Leadership and certifications in project management, grant writing, organization development, and coaching. $\mathrm{He}$ was a Navy Pilot with experience in IT, transportation, and consulting.

Dr. Matthew Earnhardt is the Chair of the Department of Organizational Leadership for ERAU-W. He holds a Ph.D. in Organizational Leadership. He has a background in the intelligence field and is a consultant in organization development. He holds certifications as an MBTI practitioner and grant writer.

Dr. Linda Pittenger is a tenured, Associate Professor of Organizational Leadership and Director of Faculty Development at ERAU-W. Her research focuses on emotional intelligence, behavioral competencies, and shared vision. She spent two decades in Fortune 100 executive positions and served as a Commissioner for President Obama's Tech America initiative.

Dr. Robin Roberts is an educator with 40 years' experience in organizational development. She specializes in designing courses and programs in leadership, organizational development, and cross-cultural dexterity. She currently works as an Assistant Professor at ERAU-W teaching undergraduate and graduate level courses in the College of Business.

Dr. Kees Rietsema is a tenured, Associate Professor of Organizational Leadership at ERAU-W. He holds a Ph.D. in Organizational Management with broad leadership experience in the military, business and academia. He is a certified coach with interests in complex adaptive leadership and organizational change.

Dr. Janet Cosman-Ross is an Assistant Professor at ERAU-W. She teaches graduate and undergraduate courses dealing with ethics, accounting and organizational development. She has a background in corporate finance and is certified in project management. 